\title{
PENGENALAN SEJARAH KEBUDAYAAN ISLAM (SKI) PADA MAN 1 PAGAR ALAM BERBASIS ANDROID
}

\author{
Buhori Muslim $^{1}$, Ayu Lestari² \\ ${ }^{1,2}$ Teknik Informatika, Sekolah Tinggi Teknologi Pagaralam email: \\ buhoristtp@gmail.com ${ }^{1}$ Ayusandarangin2019@gmail.com ${ }^{2}$
}

\begin{abstract}
This study aims to design and build an Application for Introduction to Islamic Cultural History at MAN 1 Pagar Alam based on Android which attracts students' interest in learning. The background of this research is learning that still uses conventional media which makes it difficult for teachers so that it takes a long time and makes students bored when learning takes place. Application for Introduction to the History of Islamic Culture was developed using the Adobe Flash Professional CS6 and Xampp applications as server software to the MySql database. This study uses the Analysis Design Development Implementation Evaluation (ADDIE) system development method, because this method is easier to understand and has a good research product development stage. To measure the level of student interest in the application used test instruments, namely expert reviews of experts, field tests or alpha and beta tests obtained from the results of the pretest and posttest to see the level of understanding and interest of students before and after using the learning animation application of Islamic Cultural History subjects.
\end{abstract}

Keywords: Application, Introduction, History of Islamic Culture, ADDIE.

\begin{abstract}
Abstrak
Penelitian ini bertujuan merancang dan membangun Aplikasi Pengenalan Sejarah Kebudayaan Islam (SKI) pada MAN 1 Pagar Alam Berbasis Android yang menarik minat siswa dalam belajar. Latar belakang penelitian ini yaitu pembelajaran yang masih menggunakan media konvensional yang merepotkan pengajar sehingga memakan waktu yang lama dan membuat siswa menjadi bosan pada saat pembelajaran berlangsung. Aplikasi Pengenalan Sejarah Kebudayaan Islam (SKI) di kembangkan dengan menggunakan aplikasi Adobe Flash Professional CS6 dan Xampp sebagai software server ke database MySql. Penelitian ini menggunakan metode pengembangan sistem Analisis Design Development Implementation Evaluation (ADDIE), karena metode ini lebih mudah dipahami dan mempunyai tahapan pengembangan produk penelitian yang baik. Untuk mengukur tingkat minat siswa pada aplikasi digunakan instrumen tes yaitu expert review para ahli, field test atau uji alpha dan beta yang diperoleh dari hasil pretest dan posttest untuk melihat tingkat pemahaman dan minat siswa sebelum dan sesudah penggunaan aplikasi animasi pembelajaran mata pelajaran Sejarah Kebudayaan Islam (SKI).
\end{abstract}

Kata kunci: Aplikasi, Pengenalan, Sejarah Kebudayaan Islam, ADDIE

\section{PENDAHULUAN.}

Perkembangan teknologi informasi di dunia berkembang pesat. Teknologi telah berkembang berbagai bidang kehidupan yang membantu pekerjaan manusia dalam bidang pendidikan maupun pekerjaan sehari-hari [1] bisa dikerjakaan bantuan teknologi atau bahkan bisa menggantikan pekerjaan manusia [2], perkembangan teknologi saat ini salah satunya yaitu pada bidang multimedia [3]. Makin berkembang teknologi di era digital ini, pengguna teknologi tidak bisa lepas dari peran media-media baru tersebut yang dalam penyajianya terus menampilkan animasi, baik pada media televisi, layar lebar, sampai penggunaan sederhana [4]. Termasuk untuk kegiatan belajar mengajar di Sekolah telah mengaplikasikan teknologi multimedia [5].

Proses mengajar mata pelajaran Sejarah Kebudayaan Islam (SKI) ini masih mengikuti cara konvensional menggunakan papan tulis dan buku, diakhir pelajaran guru memberikan soal-soal dari buku [6]. Proses pembelajaran dengan menggunakan metode tersebut masih kurang efektif, kurangnya alat bantu dalam penyampaian materi membuat kesulitan bagi guru dalam penyampaian materi sehingga siswa kurang maksimal memahami materi, membuat siswa mudah jenuh dan mengantuk saat proses belajar berlangsung. maka dari itu 
peneliti membuat aplikasi pengenalan untuk mempermudah proses belajar Sejarah Kebudayaan Islam (SKI).

Berdasarkan latar belakang maka peneliti membuat sebuah Aplikasi Pengenalan Sejarah Kebudayaan Islam (SKI) Pada MAN 1 Pagar Alam Berbasis Android diharapkan mampu mempermudah peroses belajar. Rumusan penelitian ini "Bagaimana merancang \& bangun aplikasi pengenalan Sejarah Kebudayaan Islam (SKI) pada MAN 1 Pagar Alam Berbasis Android ?".

\section{METODE PENELITIAN}

Metode penelitian merupakan langkah- langkah yang dilakukan oleh peneliti dalam mengumpulkan informasi ataupun data yang mendukung dalam pembuatan aplikasi [7].

\section{Metode Pengumpulan Data}

Metode pengumpulan data yang digunakan dalam penyusunan skripsi ini terdiri dari beberapa macam metode, yaitu: Wawancara, Kuisioner, Observasi [8].

Metode Pengembangan Sistem Pengembangan sistem menggunakan metode ADDIE pada penelitian Model pendekatan ini meliputi analisis, desain, development, implementasi \& evaluasi (ADDIE) [9].

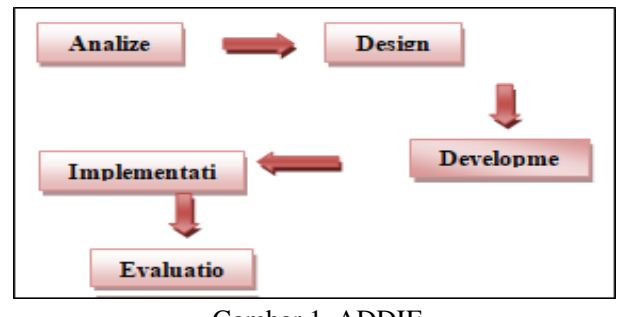

Gambar 1. ADDIE

\section{HASIL DAN PEMBAHASAN}

\section{Multimedia}

Multimedia secara terminologis yaitu gabungan berbagai media seperti teks, gambar, suara, animasi, video dan lain- lain yang saling berkaitan, dibuat melalui komputer atau peralatan elektronik lain untuk mencapai tujuan tertentu [10-11].

\section{Sejarah Kebudayaan Islam (SKI)}

Sejarah merupakan kisah atau cerita berkesan dimana kisah tersebut terjadi dimasa lampau yang menjadi kisah atau pengalaman terjadi oleh manusia. Sedangkan kebudayaan itu penjelmaan akal \& rasa manusia. berarti manusia yang menciptakan kebudayaan baik kebudayaan masa lampau yang sampai sekarang masih dikembangkan atau sudah menjadi sebuah kisah. Kebudayaan Islam, berarti kebudayaan atau suatu kegiatan yang tidak melenceng dari ajaran Islam [12].

\section{Android}

Noor (2006) Android sebuah sistem dikembangkan Google OS Android bisa digunakan untuk tablet dan smartphone. Android merupakan robot pintar yang dibuat menyerupai manusia yang dapat mengerjakan sesuatu yang dikerjakan manusia [13].

\section{Sistem diusulkan}

Berdasarkan metode pengumpulan data dan penelitian untuk kebutuhan sistem, peneliti membangun flowchat sistem yang diusulkan.

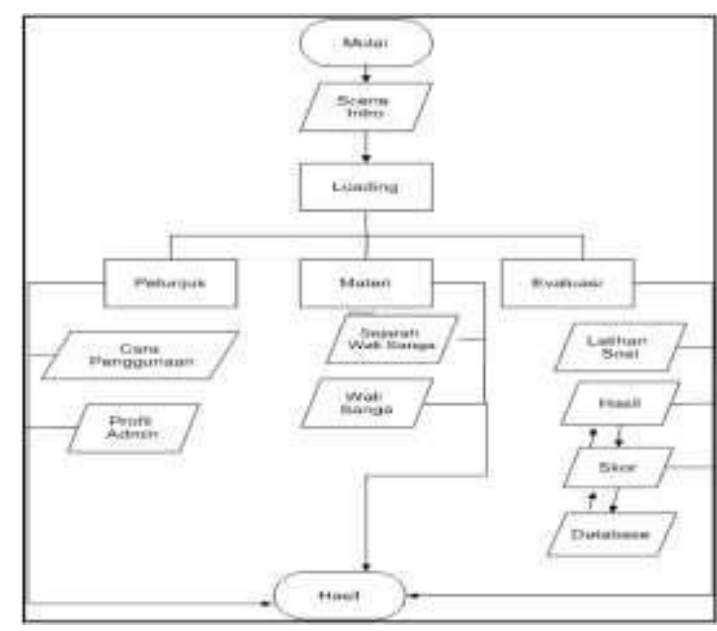

Gambar 2. Flowchat sistem diusulkan [14-15]

\section{Desain}

Berikut merupakan desain beberapa scene yang dibuat pada aplikasi ini:

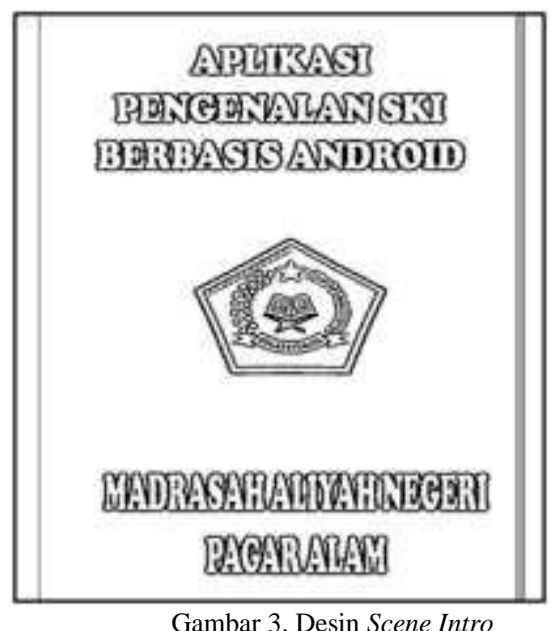

Gambar 3. Desin Scene Intro 


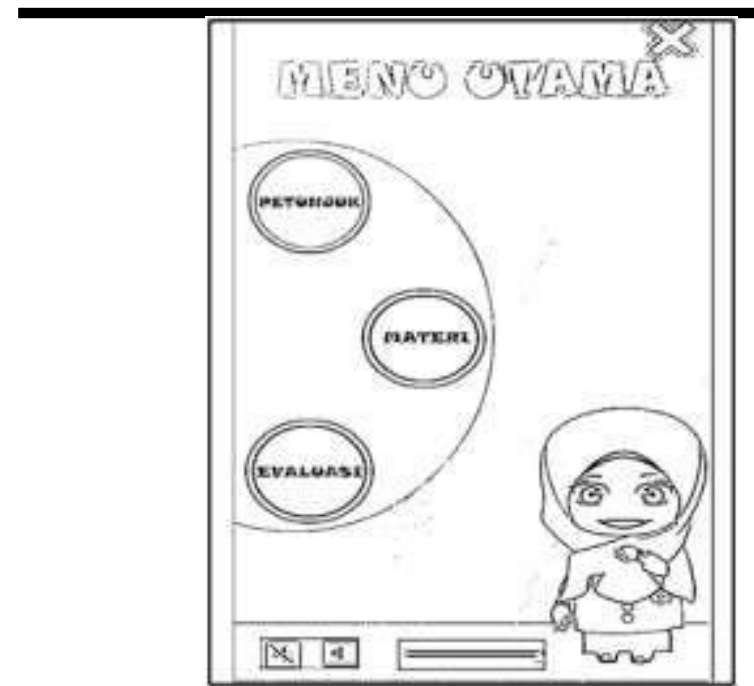

Gambar 4. Desain Menu Utama

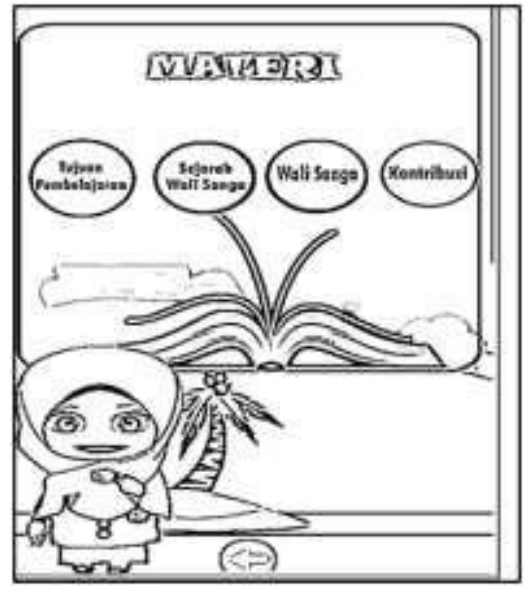

Gambar 5. Desain Menu Materi

Tampilan ini merupakan tampilan awal yang ada pada aplikasi pengenalan SKI pada MAN 1 Pagar Alam.

\section{Pembahasan Hasil.}

Hasil yang diperoleh dari penelitian ini berupa Aplikasi Pengenalan Sejarah Kebudayaan Islam (SKI) pada MAN Pagar Alam Berbasis Android. Adanya aplikasi ini dapat membantu proses belajar bagi guru maupun siswa.

\section{Tampilan Scane Intro}

Halaman ini merupakan halaman pembuka pada aplikasi pengenalan Sejarah Kebudayaan Islam (SKI) saat program pertama kali di buka maka dihadapkan tampilan pertama dengan tombol untuk mulai masuk dalam aplikasi.

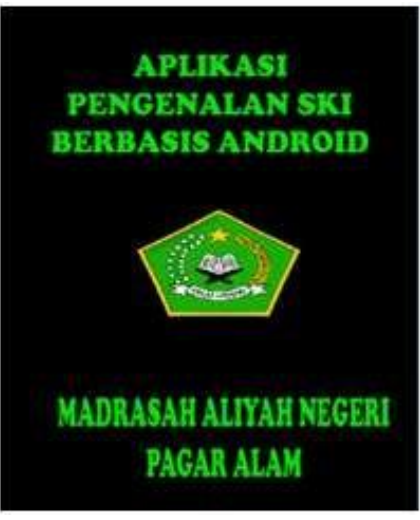

Gambar 6. Scene Intro

\section{Tampilan Menu Utama}

Setelah scane intro dan loading siswa dihadapkan pada tampilan menu utama yang terdiri dari menu petunjuk, menu materi dan menu evaluasi.

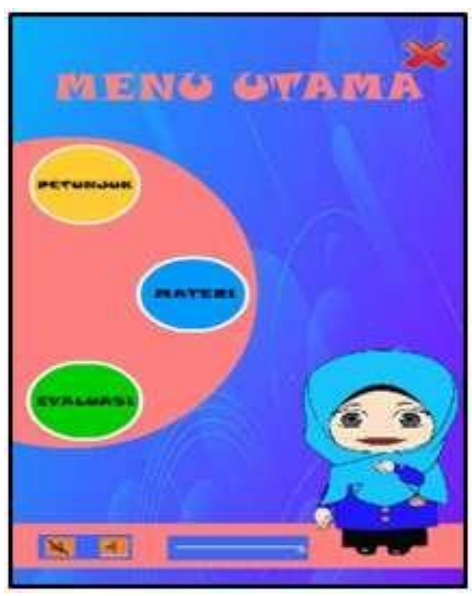

Gambar 7. Menu Utama

\section{Tampilan Menu Materi}

Didalam menu materi siswa akan dihadapkan pada pilihan menu utama yang terdidiri dari 2 (dua) pilihan menu, yaitu sejarah Wali Sanga dan Wali Sanga.

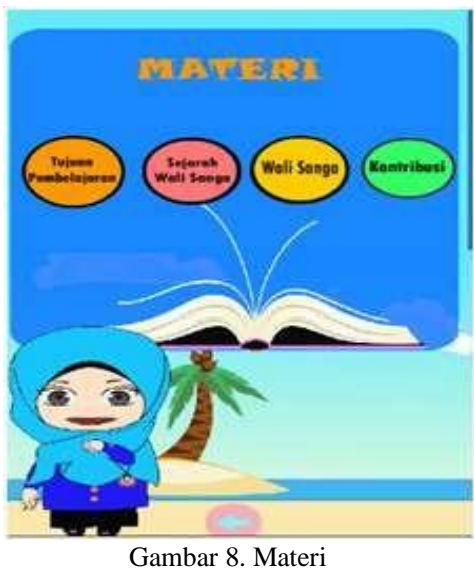


Penilaian

\section{Ahli}

Development.

Penilaian ahli validitas yaitu Penilaian Ahli Bahasa, Ahli Materi, Ahli Media dan Ahli Desain. hasil pada uji bahasa didapatkan skor rata-rata 3,8 uji materi didapatkan skor 3,8 uji desain mendapatkan skor 4,1 dan ahli media mendapatkan skor 4,1 , sehingga hasil rata- rata 3,95 dengan kategori valid. Hal ini menunjukan aplikasi pengenalan Sejarah Kebudayaan Islam (SKI) sudah menunjukan produk yang Valid. Berikut grafik Validator:

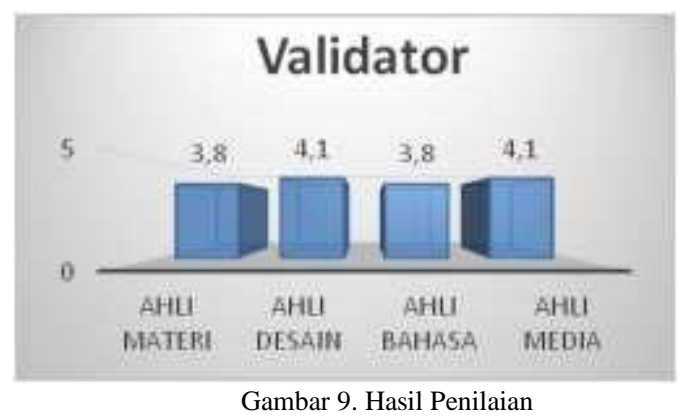

\section{Implementasi (Field test).}

hasil field test didapatkan nilai rata-rata yang dicapai siswa saat pre-test adalah 34,0 dengan kategori sangat kurang, sedangkan untuk hasil post test didapatkan hasil 87,0 dengan kategori baik. Kemudian berdasarkan data tesebut didapatkan $N$-gain sebesar 0,81 yang menunjukan bahwa aplikasi pengenalan Sejarah Kebudayaan Islam (SKI) memiliki kefektifan terhadap hasil belajar siswa.

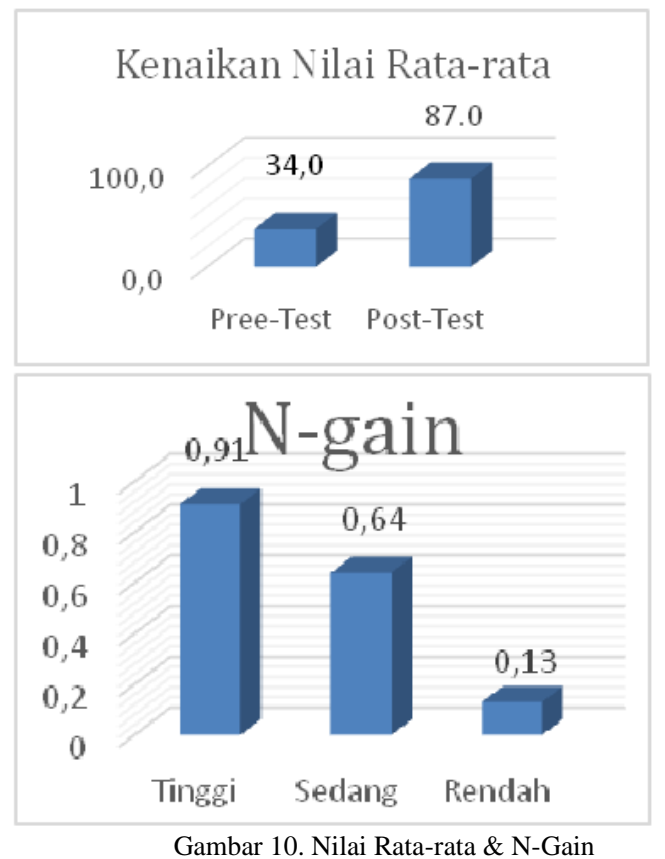

\section{SIMPULAN DAN SARAN}

Kesimpulan penelitian ini adalah Aplikasi pengenalan Sejarah Kebudayaan Islam (SKI) dibuat menggunakan aplikasi Adobe Flash Professional CS6 dan Database MySql Yang dapat mempermudah peroses belajar. Dari hasil validasi didapatkan Hasil validasi aplikasi dengan kriteria sangat valid dengan hasil rata-rata 3,95 dengan kategori valid. Hasil field test atau uji alpa dan beta data diperoleh dari hasil pretest dan post test pada uji lapangan yaitu dengan nilai rata rata 87,0 .

\section{TERIMA KASIH}

Terima kasih Kepada MAN 1 Pagar Alam.

\section{DAFTAR PUSTAKA}

[1] Muslim, B. (2017). Pengantar Teknologi Informasi, 1st ed., Emy RF, Ed. Yogyakarta, Indonesia: Deepublish.

[2] Muslim, B. dkk, (2017), Sistem Pakar Diagnosa Awal Penyakit Ginjal Berbasis Web Menggunakan PHP \& Mysql, Jurnal Ilmiah Betrik, Vol. 08, No.03, pp 116-122.

[3] Aminah, S. (2018). Rancang Bangun Aplikasi Education Game Pembelajaran Bahasa Inggris Berbasis Multimedia Pada Smp Negeri 8 Pagaralam. Jurnal Ilmiah Betrik.

[4] Ruslan, A. (2016). Animasi Perkembangan \& Konsepnya. Bogor: Ghalia Indonesia.

[5] Putrawansyah, F. (2018). Multimedia Pembelajaran Simulasi Instalasi Sistem Operasi Windows Dan Software Pendukung Pada Mata Kuliah Praktikum Sistem Operasi Sekolah Tinggi Teknologi Pagar Alam. Jurnal Betrik, 70-83.

[6] Juanda, M. S., \& N. H. (2019). Rancang Bangun Aplikasi Sejarah Kebudayaan Aceh Berbasis Android Studi Kasus Dinas Kebudayaan Dan Pariwisata Aceh. Journal Of Informatics And Computer Science.

[7] Muslim, B. (2018). Analisis system informasi (SI) terintegrasi di Perguruan Tinggi (PT) (Studi Kasus: STT Pagaralam). Jurnal Teknologi Informasi MURA, Vol 10. Page 8391. 
[8] Sugiyono, P. D. (2011). Metode Penelitian Kombinasi (Mixed Methods). Bandung: Alfabeta.

[9] Aminah, S. (2018). Implementasi Model Addie Pada Education Game Pembelajaran Bahasa Inggris (Studi Kasus Pada Smp Negeri 8 Pagaralam. Jurnal Ilmiah Betrik.

[10] Purnama, B. E, \& Wawan, S. (2012). Pengembangan Multimedia Pembelajaran Interaktif Untuk Mata Kuliah Organisasi Komputer. Sentra Penelitian Engineering Dan Edukasi, 60- 67.

[11] Muslim, B. dkk. (2017). Aplikasi Pembelajaran Interaktif pada Mata Kuliah Maintenance pada Program Studi Teknik Informatika Sekolah Tinggi Teknologi Pagar Alam, Indonesian Journal of Computer Science (IJCS). Vol. 6, No. 2, pp 125-135.

[12] Dra. Hj. Aminah, M. (2017). Pendidikan Agama Islam Untuk Perguruan Tinggi. Yogyakarta: Cv. Andi Offset.

[13] Noor, A. (2016). Aplikasi Kisah 25 Nabi Dan Rasul Berbasis Android. Jurnal Sains \& Informatika.

[14] Gusmaliza, D. (2019). Perangkat Lunak Bantu Administrasi Keuangan Sekolah Tinggi Teknologi Pagar Alam Dengan Php Dan Mysql. Jurnal Ilmiah Betrik.

[15] Muslim, B. dkk. (2019), Proposal of infrastructure information technology Frame work togaf for pagar alam town governance, Jurnal Teknologi Informasi Mura, Vol. 11 No.01, pp 20-28. 